\title{
Clinical effectiveness of grip strength in predicting ambulation of elderly inpatients
}

This article was published in the following Dove Press journal:

Clinical Interventions in Aging

3 November 2014

Number of times this article has been viewed

MR Beseler'

C Rubio'

E Duarte'

D Hervás ${ }^{2}$

MC Guevara'

M Giner-Pascual'

E Viosca'

'Physical Medicine and Rehabilitation, La Fe Hospital, Valencia, Spain;

${ }^{2}$ Statistical Unit, La Fe Hospital,

Valencia, Spain
Correspondence: MR Beseler

Catarroja 2, 46210 Picanya, Valencia,

Spain

Email beseler_ros@gva.es
Background: Assessing the clinical effectiveness of measuring grip strength as a prognostic tool in recovering ambulation in bed-confined frail elderly patients.

Methods: A prospective study was carried out with 50 elderly inpatients (mean age: 81.6 years old). Manual muscle test was used for checking strength of hip flexor muscles, hip abductor muscles and knee extensor muscles. Grip strength was assessed by hydraulic dynamometer. Walking ability was assessed by functional ambulation categories and Functional Classification of Sagunto Hospital Ambulation. Existence of cognitive impairment (Short Portable Mental Status of Pfeiffer) and comorbidity (abbreviated Charlson index) were considered to be confounding variables.

Statistical analysis: Simple comparisons and mixed models of multiple ordinal regression. Results: The sample presented generalized weakness in scapular (mean 4.22) and pelvic (mean 3.82) muscle. Mean hand grip values were similar: $11.98 \mathrm{~kg}$ right hand; $11.70 \mathrm{~kg}$ left hand. The patients had lost walking ability. After treatment, there was a statistically significant for scapular waist strength $(P=0.001)$, pelvic waist strength $(P=0.005)$ and walking ability $(P=0.001)$. A statistically significant relationship in the regression analysis was found between the grip (right and left hands) and walking ability post-treatment ( $P=0.009$; odds ratio 1.14 and $P=0.0014$ odds ratio 1.113 for each walking scale). The confounding variables showed no statistical significance in the results.

Conclusion: Grip strength is associated with walking ability in hospitalized frail elderly. Grip strength assessment by hydraulic dynamometry is useful in patients with poor collaboration. Walking ability training in frail elderly inpatients is useful.

Keywords: gait, elderly, hand grip, physical therapy

\section{Introduction}

Loss of muscle strength and skeletal muscle mass due to aging, known as sarcopenia, generates disability, increased morbimortality, and prolonged hospitilization. ${ }^{1}$ Loss of walking ability due to bedridden condition is common in the hospitalized frail elderly for several reasons. In many cases, the ability to walk was poor previously, so their functional condition is aggravated. This is a frequent reason for consultations for rehabilitation facilities, especially in intermediate hospitalization centers.

Often, physical function assessment in these patients is very difficult because they do not understand the exploratory maneuvers due to cognitive impairment or confusion. So we need simple assessment tools to obtain objective information about their physical condition in order to design the best rehabilitative plan within the shortest possible inpatient time. There are no studies about a rational and easy assessment of physical function in frail elderly inpatients. 
There is a well-established relationship between upper and lower limb strength and grip strength, specifically between grip strength and hip and knee muscle strength in the adult population. ${ }^{2,3}$ Asking a patient to exercise grip strength is relatively easy as it is an intuitive action with good motivational interest that can be done at the patient's bedside, and even with a limited level of comprehension.

From this assumption the authors propose that the present study aimed to assess the clinical effectiveness of grip strength as a tool for the assessment of muscle strength and thus as a predictive measure of gait recovery of hospitalized frail elderly patients.

\section{Materials and methods}

A prospective study was carried out with 77 consecutive hospital inpatients of geriatric age in a medium- and longterm unit (from La Fe Hospital in Valencia, Spain) admitted for decompensated chronic pathology or acute disabling pathology with loss of walking ability. Clinical instability and terminal condition states were considered as the exclusion criteria.

Patients were enrolled between October 2011 and September 2013. The average bedridden time was 17 days.

Causes of ambulation loss were, in descending order, pulmonary or cardiac pathology decompensation (26.6\%), infectious processes $(24.1 \%)$, and neoplastic processes $(12.7 \%)$.

Training was adapted to the patient's physical conditions in sessions of three times a week for 30-45 minutes per session. It included archway joint exercises, limb strengthening exercises, standing balance exercises, and gait training re-education with walking aid assistance. In the most favorable cases, aerobic indoor training was included with a bicycle ergometer.

Patients were assessed at the beginning and reassessed once they had reached the ambulation level indoors or after they had completed a 4 week training period independently of the functional outcome. All patients were evaluated by the same researcher. All subjects gave written informed consent.

Of the 77 initial patients, 50 completed the study. Reasons for abandonment were medical causes $(47.8 \%)$ as clinical deterioration or death, and social reasons: transfer to a residence, early discharge without completed training, and voluntary discharge.

The mean age of this sample was 81.6 years (65-95 years), and it was homogeneous in terms of sex distribution (25 males, 25 females).

\section{Assessment methods}

- Mean manual muscle test $(\mathrm{MMT})^{4}$ of scapular and pelvic waists. Tested muscles were: shoulder abduction muscles, elbow flexion and extension muscles, hip flexion and abduction muscles, and knee extension muscles of both upper and lower limbs.

- Manual passive joint arch exam of upper and lower limbs in order to assess restrictions with a possible impact on gait training.

- Hand grip strength was measured with a hydraulic hand dynamometer (Baseline ${ }^{\circledR}$ measurements; Fabrication Enterprises Inc, Elmsford, NY, USA) according to the standard protocol, which employs the mean of three strength tests as the resultant score for both hands. For each grip strength test, the subject was seated or placed in a semi-seated position (according to the patient's clinical conditions) with shoulder adducted and neutrally rotated, elbow flexed at $90^{\circ}$, forearm in a neutral position, and wrist between $0^{\circ}$ and $30^{\circ}$ dorsiflexion and between $0^{\circ}$ and $15^{\circ}$ ulnar deviation.

- Walking was assessed according to the following scales: functional ambulation categories $(\mathrm{FAC})^{5}$ and Functional Classification of Sagunto Hospital Ambulation (CFMHS in Spanish). ${ }^{6}$

- Assessment of cognitive impairment as a confounding variable by the Pfeiffer Short Portable Mental Status., ${ }^{7.8}$

- Recording comorbidity factors through the abbreviated Charlson index. ${ }^{9}$

\section{Statistical analysis}

- Simple comparison analyses and mixed models analyses were applied. For each variable, the entry criteria was $P<0.05$.

- A Wilcoxon test was used to compare paired samples before and after treatment.

- Multivariable ordinal regression was used to assess the relationship between response variables (CFMHS scale, FAC scale, and muscle limb strength) and grip strength as a predictor variable.

All the analyses were performed with R software (version 2.15.3).

\section{Results}

The sample with 50 patients who completed the study exhibited age-appropriate joint mobility $(91.8 \%$ without restrictions in upper limbs; $77.2 \%$ without significant restrictions in lower limbs). As shown in Table 1 they displayed muscle weakness, which was greater in pelvic muscles than in 
Table I Wilcoxon test results

\begin{tabular}{|c|c|c|c|c|c|c|}
\hline & Scapular MMT & Pelvic MMT & Right grip (kg) & Left grip (kg) & FAC & CFMHS \\
\hline \multicolumn{7}{|l|}{ Pre-treatment } \\
\hline Mean (SD) & $4.22(0.65)$ & $3.82(0.85)$ & $11.98(6.12)$ & $11.70(5.90)$ & $0.74(1.02)$ & $0.56(0.76)$ \\
\hline Median (IQR) & $4(4-5)$ & $4(3-4)$ & $10(9-15)$ & $10(8-15)$ & $0(0-1.75)$ & $0(0-I)$ \\
\hline \multicolumn{7}{|l|}{ Post-treatment } \\
\hline Mean (SD) & $4.62(0.53)$ & $4.29(0.76)$ & $13.19(6.88)$ & I2.83 (5.95) & $2.60(1.07)$ & $1.90(0.84)$ \\
\hline Median (IQR) & $5(4-5)$ & $4(4-5)$ & $12(9-17)$ & $13(8-17)$ & $3(2-3)$ & $2(1.25-2)$ \\
\hline \multicolumn{7}{|l|}{ Change } \\
\hline Mean & 0.40 & 0.45 & 1.87 & 1.39 & 1.86 & 1.34 \\
\hline Pseudo-median & 0 & I & I & I & 2 & I \\
\hline Significance & 0.001 & 0.005 & 0.33 & 0.25 & $<0.001$ & $<0.001$ \\
\hline $95 \% \mathrm{Cl}$ & {$[0,1]$} & {$[0,1]$} & {$[-1,3]$} & {$[-1,4]$} & {$[2,3]$} & {$[1,2]$} \\
\hline
\end{tabular}

Notes: Mean values and median statistical values (in parentheses) reflect muscle strength in the scapular and pelvic waists, grip strength and walking ability before and after treatment, as well as statistical significance.

Abbreviations: MMT, manual muscle test; FAC, functional ambulation categories; CFMHS, CFMHS Classification of Sagunto Hospital Ambulation (Spanish); SD, standard deviation; IQR, interquartile range; $\mathrm{Cl}$, confidence interval.

scapular muscles. The mean grip strength values were similar between upper limbs. In disability terms, patients were in a bedridden condition. Regarding the comorbidity index, $22.9 \%$ of the sample (eleven patients) had no comorbidity ( $0-1$ points in the Charlson index), 35.4\% (17 patients) displayed a low degree of comorbidity ( 2 points) and $41.7 \%$ (20 patients) exhibited a high degree of comorbidity ( $\geq 3$ points). Of all the patients, $42.9 \%$ presented with cognitive impairment according to the Pfeiffer test.

\section{Wilcoxon test results}

The mean values, standard deviations (in parentheses), median values, and interquartile ranges (in parentheses) reflect muscle strength in the scapular and pelvic waists, grip strength and walking ability before and after treatment, as well as statistical significance (Table 1).

As shown, the scapular and pelvic muscle strength values were higher in the second assessment than in the first one. Likewise, walking ability improved with training as shown by the FAC and CFMHS scales. The Wilcoxon test supports that the differences between the pre- and post-treatments for muscle strength and walking ability are statistically significant $(P<0.001)$.

\section{Multivariable ordinal regression complex contrasts}

The multiple ordinal regression analysis (Table 2) confirms a statistically significant association between grip strength and both muscle scapular strength $(P<0.001$, odds ratio $[\mathrm{OR}]=1.52$ of being in a higher category per $1 \mathrm{~kg}$ increase in grip strength) and pelvic waist strength $(P=0.002, \mathrm{OR}=1.16$ of being in a higher category per $1 \mathrm{~kg}$ increase in grip strength) at the baseline of the study.
A statistically significant relationship was also found pre-treatment between grip strength (right or left) and walking ability on both the FAC ( $P=0.009$, OR $=1.14$ of being in a higher category per $1 \mathrm{~kg}$ increase in grip strength) and CFMHS scales $(P=0.014$, OR $=1.13$ of being in a higher category per $1 \mathrm{~kg}$ increase in grip strength). We also assessed whether higher grip strength values were associated with better improvement in the FAC and CFMHS scales after training. We found that higher baseline grip strength showed a trend, although not statistically significant, to a better recovery after treatment on the FAC scale $(P=0.08, \mathrm{OR}=1.08)$, and also on the CFMHS scale $(P=0.12, \mathrm{OR}=1.07)$.

At the same time, cognitive impairment and comorbidity degree variables showed no significant statistical influence on the ambulation training results $(P$-value $=0.25$ for the Charlson index and $P$-value $=0.60$ for cognitive impairment).

\section{Discussion}

We found that the frail elderly population of our study, with loss of walking ability due to clinical intercurrences, shows generalized weakness in all four limbs and diminished physical fitness. This condition is known as sarcopenia according to the European Consensus Group. ${ }^{10}$ Weakness is slightly greater in the lower limbs than in the upper limbs (scapular/pelvic rate: 0.91). Grip strength, pelvic

Table 2 Multivariate ordinal regression complex contrasts

\begin{tabular}{lllll}
\hline & Scapular MMT & Pelvic MMT & FAC & CFMHS \\
\hline Grip & $P<0.001$ & $P<0.002$ & $P<0.009$ & $P<0.0014$ \\
& OR I.52 & OR I.16 & OR I.14 & 1.113 \\
\hline
\end{tabular}

Abbreviations: MMT, manual muscle test; FAC, functional ambulation categories; CFMHS, CFMHS Classification of Sagunto Hospital Ambulation (Spanish); OR, odds ratio. 
waist strength, scapular waist strength and walking ability improved significantly after treatment. Greater grip strength (right or left) values at baseline are associated with higher walking ability values according to the CFMHS and FAC scales, showing statistical significance (Wilcoxon test: $P<0.001)$. Several authors accept that grip strength is related to lower limb strength and walking ability and gait speed are related to quadriceps extension strength ${ }^{11-13}$ and that grip strength is related to lower limb strength. Our results prove this conclusion that grip and walking ability may be correlated.

The association between grip strength and FAC and CFMHS scales already existed before treatment and higher baseline grip strength shows a trend toward a better recovery after treatment, although not statistically significant. So those patients presenting with better grip strength at baseline obtained a higher score on the initial FAC and CFMHS scales and, logically, also after treatment. These differences in the relationships between both scales with grip strength can be explained by there being no direct relationship between deficiency (strength) and disability (walking ability). Therefore, the ordinal levels of each scale are not exactly the same between each other.

Bohannon considers that the grip strength measurement correlates with lower limb strength, and that it is a logical construct in a healthy adult population ${ }^{14}$ and quadriceps strength in patients receiving physiotherapy, ${ }^{2}$ or as a disability predictor in aged populations. ${ }^{15}$ Our results agree with this construct because our sample has revealed a statistically significant association between grip strength and scapular and pelvic waist strength $(P<0.001)$ at the baseline of the study.

Assessment of physical condition in these cases is very difficult, so we chose a simple but objective assessment tool to obtain information about their physical condition ${ }^{16}$ in order to design the best rehabilitative plan within the shortest possible inpatient time.

Based on our results, it can be inferred that physicians could use grip strength assessments to learn about lower limb strength in frail elderly inpatients who find it difficult to do the maximum muscle contractions as a measurement of MMT to establish physical training plans and to predict their future walking ability.

In functional terms, after treatment, patients shift from a non-walking situation to an indoors walking situation. Although this situation does not permit independent walking ability, it can mean a significant change to primary caregivers and the family. These results support the effectiveness of physical therapy in frail elderly populations to re-establish minimum walking ability which, according to previous studies, makes the return to home after hospital admission easier. $^{17-19}$

In our study, cognitive impairment and degree of comorbidity has no statistically significant influence on the ambulation training results. One meta-analysis has proven that the result of rehabilitative treatment after hip surgery is influenced by the existence of cognitive impairment. ${ }^{20}$ Yet a systematic review by Tappendien et al proved that functional results are similar between the non-deteriorated population and those with mild or moderate dementia, ${ }^{21}$ which is in accordance with our results. The Charlson index establishes the degree of comorbidity with a predictive value for shortterm and long-term mortality. We considered the functional result to be a confounding variable because it reflects the degree of frailty of the elderly, as well as any possible clinical complications that may interfere with gait training. Our sample showed no significant influence $(P$-value $=0.81)$, which could be due to the short monitoring time of our sample and the patients' clinical stability condition to tolerate the physiotherapy session.

We think that the originality of our study is to demonstrate the usefulness of a single measurement system for frail elderly inpatient, whose physical and cognitive conditions make it quite difficult assessing physical function. The limitation of our study is the loss of patients due to various reasons, reducing statistical power. We believe that continuing this research line will strengthen these results.

\section{Conclusion}

Grip strength assessed by hydraulic dynamometry is associated with walking ability in the hospitalized frail elderly and serves as a prognostic factor in the ability to walk.

The grip strength assessment by hydraulic dynamometry is useful in patients with poor collaboration due to cognitive impairment and varying degrees of comorbidity.

Physical therapy is useful in ambulation training for frail elderly inpatients, even with cognitive impairment and comorbidity.

\section{Disclosure}

The authors have no conflicts of interest to disclose.

\section{References}

1. Cawthon PM, Marshall LM, Michael Y, et al. Frailty in older men: prevalence, ambulation, and relationship with mortality. $J$ Am Geriatr Soc. 2007;55(8):1216-1223.

2. Bohannon RW. Are hand-grip and knee extension strength reflective of a common construct? Percept Mot Skills. 2012;114(2): 514-518. 
3. Arnold CM, Warkentin KD, Chilibeck PD, Magnus CR. The reliability and validity of handheld dynamometry for the measurement of lower-extremity muscle strength in older adults. $J$ Strength Cond Res. 2010;24(3):815-824.

4. Medical Research Council. Aids to the investigation of peripheral nerve injuries. War Memorandum No 7; London. His Majesty’s Stationery Office; 1943.

5. Holden MK, Gill KM, Magliozzi MR. Gait assessment for neurologically impaired patients. Standards for outcome assessment. Phys Ther. 1986;66(10):1530-1539.

6. Viosca E, Martínez JL, Almagro P, García A, González C. Proposal and validation of a new functional ambulation classification scale for clinical use. Arch Phys Med Rehabil. 2005;86(6):1234-1238.

7. Pfeiffer E. A short portable mental status questionnaire for the assessment of organic brain deficit in elderly patients. J Am Geriatr Soc. 1975;23(10):433-441.

8. Martinez J, Duenas R, Onis MC, Aguado C, Albert C, Luque R. Adaptación y validación al castellano del cuestionario de Pfeiffer (SPMSQ) para detectar la existencia de deterioro cognitivo en personas mayores de 65 años [Spanish language adaptation and validation of the Pfeiffer's questionnaire (SPMSQ) to detect cognitive deterioration in people over 65 years of age]. Medicina Clinica. 2001;117(4):129-134. Spanish.

9. Charlson ME, Pompei P, Ales KL, McKenzie CR. A new method of classifying prognostic comorbidity in longitudinal studies: development and validation. J Chron Dis. 1987;40(5):373-383.

10. Cruz-Jentoft AJ, Baeyens JP, Bauer JM, et al. Sarcopenia: European consensus on definition and diagnosis: Report of the European Working Group on Sarcopenia in Older People. Age Ageing. 2010;39(4): $412-423$.

11. Judge JO, Underwood M, Gennosa T. Exercise to improve gait velocity in older persons. Arch Phys Med Rehabil. 1993;74(4):400-406.
12. Rantanen T, Guralnik JM, Sakari-Rantala R, et al. Disability, physical activity, and muscle strength in older women: the Women's Health and Aging Study. Arch Phys Med Rehabil. 1999;80(2):130-135.

13. Aoyagi Y, Togo F, Matsuki S, et al. Walking velocity measured over $5 \mathrm{~m}$ as a basis of exercise prescription for the elderly: preliminary data from the Nakanojo Study. Eur J Appl Physiol. 2004;93(1-2):217-223.

14. Bohannon RW, Magasi SR, Bubela DJ, Wang YC, Gershon RC. Grip and knee extension muscle strength reflect a common construct among adults. Muscle Nerve. 2012;46(4):555-558.

15. Bohannon RW. Hand-grip dynamometry predicts future outcomes in aging adults. J Geriatr Phys Ther. 2008;31(1):3-10.

16. Roberts HC, Denison HJ, Martin HJ, et al. A review of the measurement of grip strength in clinical and epidemiological studies: towards a standardised approach. Age Ageing. 2011;40(4):423-429.

17. Mehta SP, Roy JS. Systematic review of home physiotherapy after hip fracture surgery. J Rehabil Med. 2011;43(6):477-480.

18. Courtney M, Edwards H, Chang A, Parker A, Finlayson K, Hamilton K. Fewer Emergency Readmissions and Better Quality of Life for Older Adults at Risk of Hospital Readmission: A Randomized Controlled Trial to Determine the Effectiveness of a 24-Week Exercise and Telephone Follow-Up Program. J Am Soc Geriatr. 2009;57(3):395-402.

19. Mudge AM, Giebel AJ, Cutler AJ. Exercising body and mind: An integrated approach to functional independence in hospitalized older people. J Am Geriatr Soc. 2008;56(4):630-635.

20. Perry MA, Hudson HS, Meys S, Norrie O, Ralph T, Warner S. Older adults' experiences regarding discharge from hospital following orthopaedic intervention: a metasynthesis. Disabil Rehabil. 2012;34(4):267-278.

21. Tappenden P, Campbell F, Rawdin A, Wong R, Kalita N. The clinical effectiveness and cost-effectiveness of home-based, nurse-led health promotion for older people: a systematic review. Health Technol Assess. 2012;16(20):1-72.
Clinical Interventions in Aging

\section{Publish your work in this journal}

Clinical Interventions in Aging is an international, peer-reviewed journal focusing on evidence-based reports on the value or lack thereof of treatments intended to prevent or delay the onset of maladaptive correlates of aging in human beings. This journal is indexed on PubMed Central, MedLine,

\section{Dovepress}

CAS, Scopus and the Elsevier Bibliographic databases. The manuscript management system is completely online and includes a very quick and fair peer-review system, which is all easy to use. Visit http://www.dovepress. com/testimonials.php to read real quotes from published authors. 